\title{
Prelimbic Cortex and Ventral Tegmental Area Modulate Synaptic Plasticity Differentially in Nucleus Accumbens During Cocaine-Reinstated Drug Seeking
}

\author{
Hao-wei Shen ${ }^{* 1,2}$, Cassandra D Gipson', Martijn Huits ${ }^{3}$ and Peter W Kalivas' \\ 'Department of Neuroscience, Medical University of South Carolina, Charleston, SC, USA; ${ }^{2}$ National Institute on Drug Dependence, Peking \\ University, Beijing, People's Republic of China; ${ }^{3}$ Department of Neuroscience, Vrije University of Amsterdam, Amsterdam, The Netherlands
}

\begin{abstract}
Addictive drug use causes long-lasting changes in synaptic strength and dendritic spine morphology in the nucleus accumbens that might underlie the vulnerability to relapse. Although activity in mesocorticolimbic circuitry is required for reinstating cocaine seeking, its role in reinstatement-associated synaptic plasticity is not well characterized. Using rats extinguished from cocaine self-administration, we found potentiated synaptic strength (assessed as the AMPA/NMDA current amplitude ratio) and increased spine head diameter in medium spiny neurons in the accumbens core (NAcore). The basal changes in synaptic strength and morphology in cocaine-extinguished animals were further augmented during cocaine-induced reinstatement. Two NAcore afferents contributing to cocaine reinstatement are glutamatergic inputs from the prelimbic prefrontal cortex $(\mathrm{PL})$ and dopamine from the ventral tegmental area (VTA). Pharmacological inhibition of either PL or VTA prevented cocaine-primed reinstatement. However, inhibiting the PL further potentiated AMPA/NMDA and spine head diameter, while inactivating the VTA or the combined systemic administration of dopamine DI and D2 antagonists prevented the increase in AMPA/NMDA and spine diameter induced by cocaine priming. These data indicate that neuronal activity in the VTA and associated dopamine receptor stimulation is necessary for the synaptic potentiation in the NAcore during cocaine-induced reinstatement. Although activity in the PL was necessary for reinstatement, it inhibited synaptic potentiation initiated by an acute cocaine injection. Thus, although the PL and VTA differentially regulate the direction of synaptic plasticity induced by a cocaine-priming injection, coordinated synaptic potentiation by both NAcore afferents is necessary for cocaine-induced relapse.

Neuropsychopharmacology (2014) 39, I I69-I I77; doi:I0.1038/npp.20 I3.3 I8; published online II December 20 I3
\end{abstract}

Keywords: cocaine self-administration; synaptic plasticity; reinstatement; prefrontal cortex; accumbens core

\section{INTRODUCTION}

Drug addiction causes enduring functional impairments in neural adaptation, including modified neuroplasticity at glutamatergic synapses in the nucleus accumbens (Luscher and Malenka, 2011). For example, there is a loss of excitatory long-term potentiation (LTP) or depression (LTD) in medium spiny neurons (MSNs) measured in vivo and in brain slices containing shell or core (NAcore) of the accumbens after withdrawal from self-administered cocaine. (Kasanetz et al, 2010; Martin et al, 2006; Moussawi et al, 2009). Changes in excitatory neuroplasticity are also revealed by probing AMPA receptor trafficking, the strength of AMPA relative to NMDA-mediated currents $(\mathrm{A} / \mathrm{N}$; Luscher and Malenka, 2011; Pierce and Wolf, 2013; Wolf and Ferrario, 2010), and dendritic spine remodeling (Robinson and Kolb,

\footnotetext{
*Correspondence: Dr H-w Shen, National Institute on Drug Dependence, Peking University, 38 Xueyuan Road, Beijing 100191, People's Republic of China, Tel: +86 1082802470 (ext. 520),

Fax: +86 10 62032624, E-mail: shenhw@hsc.pku.edu.cn

Received 5 August 2013; revised 10 October 2013; accepted 16 October 2013; accepted article preview online I5 November 2013
}

2004; Russo et al, 2010; Shen et al, 2009) in animal models of cocaine addiction.

In addition to prefrontal cortical and allocortical glutamatergic afferents, the NAcore GABAergic MSNs receive dense dopaminergic innervation from the ventral tegmental area (VTA) (Fallon et al, 1978). Both glutamatergic and dopaminergic afferents to NAcore MSNs regulate various motivated behaviors thought to model aspects of drug addiction, including locomotor sensitization, conditioned place preference, intravenous self-administration, and reinstated drug seeking (Feltenstein and See, 2008; Robinson and Berridge, 2000; Sesack and Grace, 2010; Stewart et al, 1984; Stuber et al, 2011). Specifically relevant to the experiments described herein, pharmacological or optogenetic inactivation of neuronal activity in either prelimbic cortical (PL) or VTA afferents to the NAcore prevents cocaine- or cue-induced reinstatement of cocaine seeking (McFarland and Kalivas, 2001; McLaughlin and See, 2003; Stefanik et al, 2013a; Stefanik et al, 2013b; Sun et al, 2005).

Recently, we used whole-cell patch recordings to obtain a ratio of AMPA and NMDA glutamate currents $(\mathrm{A} / \mathrm{N})$, combined with measures of dendritic spine morphology to show that cue- or context-induced reinstatement of cocaine 
or nicotine seeking induces rapid, reversible LTP-like synaptic potentiation in glutamatergic synapses on MSNs in the NAcore that required activity in PL afferents (Gipson et al, 2013a; Gipson et al, 2013b; Stankeviciute et al, 2013). In addition to drug-associated cues and context, using cocaine can trigger a desire for drug use in human addicts (O'Brien and Gardner, 2005). However, cocaine-induced craving in humans and reinstated drug seeking in animals is associated with acute pharmacological drug effects, such as enduring increases in dopamine transmission, that may differentially affect reinstatement-associated neuroadaptations (Ito et al, 2002; Volkow et al, 2006). To determine whether reinstatement-associated LTP may differ between cocaine-induced reinstatement compared with cue- or context-induced reinstatement, rats were extinguished from daily cocaine self-administration and lever pressing reinstated by an acute, noncontingent injection of cocaine. We measured $\mathrm{A} / \mathrm{N}$ and spine morphology in MSNs from the NAcore during cocaineinduced reinstatement and how this plasticity was regulated by neuronal activity in the VTA or prelimbic prefrontal cortex (PL). We found that, akin to cue and context, reinstating cocaine seeking with an acute cocaine injection produced transient LTP-like synaptic potentiation. We then found that pharmacological inactivation of the VTA or PL prevented cocaine-induced reinstated cocaine seeking but differentially prevented or potentiated, respectively, reinstatement-associated synaptic potentiation.

\section{MATERIALS AND METHODS}

\section{Animals and Surgery}

All procedures were in accordance with the National Institutes of Health Guide for the Care and Use of Laboratory Animals and the Assessment and Accreditation of Laboratory Animal Care. Male Sprague Dawley rats (250 g on arrival; Charles River Laboratories, Wilmington, MA) were individually housed in a temperature- and humiditycontrolled environment with a 12-h dark/light cycle (1800 hours lights on). Experiments were conducted during the rats' dark cycle. Rats received food ad libitum until 1 day before behavioral training, after which food restriction procedures ( $20 \mathrm{~g}$ of rat chow per day) were implemented and maintained throughout the duration of the experiment. Rats were allowed 1 week to acclimate to the vivarium before inducing anesthesia and implanting jugular and intracranial cannula. The surgical details have been described in a previous study (Shen et al, 2011). Intracranial guide cannulas (26 guage) were stereotaxically implanted bilaterally into the PL (anteroposterior (AP), $+3.2 \mathrm{~mm}$; mediolateral (ML), $\pm 0.5 \mathrm{~mm}$; dorsoventral (DV), $-3.5 \mathrm{~mm}$ from bregma) or VTA (AP, +5.2 ; ML, $\pm 0.5 ; \mathrm{DV},-8.0$ ).

\section{Cocaine Self-Administration Procedures}

All self-administration experiments occurred in standard operant chambers with two retractable levers, a house light, and a cue light and tone $(78 \mathrm{~dB}, 4.5 \mathrm{kHz})$ generator (Med Associates, Fairfield, VT). During 2-h sessions on 10 consecutive days, rats were trained to press the active lever on a fixed ratio 1 schedule with 20 -s timeout for an infusion of cocaine $(200 \mu \mathrm{g}$ in $50 \mu \mathrm{l}$ sterile saline; cocaine hydro- chloride was provided by the National Institute on Drug Abuse). Concurrent with the drug infusion, a cue tone and light immediately above the active lever turned on. All animals in the study met the criterion for acquisition of cocaine self-administration, which was a minimum of 10 infusions per day over three consecutive daily self-administration sessions. Then rats began extinction training. Active lever presses produced no drug infusion or light/tone cues. Animals continued under extinction conditions for a minimum of 14 days and until $<15$ active lever presses were made per session for 3 consecutive days. For cocaineprimed reinstatement, rats received a single injection of cocaine $(10 \mathrm{mg} / \mathrm{kg}$, ip) to initiate a reinstatement session. The reinstatement session was identical to an extinction session (ie, there was no programmed consequence of active lever pressing).

\section{Drug Administration}

A mixture $(B / M)$ of the $\mathrm{GABA}_{\mathrm{B}}$ agonist baclofen $(0.1 \mathrm{nmol})$ and the $\mathrm{GABA}_{\mathrm{A}}$ agonist muscimol $(0.01 \mathrm{nmol})$ was dissolved in artificial cerebrospinal fluid (aCSF). Immediately before reinstatement testing, animals were microinjected bilaterally with either aCSF) or B/M in a volume of $0.3 \mu \mathrm{l}$ per side over $60 \mathrm{~s}$, and the injectors were left in place for $60 \mathrm{~s}$ to permit diffusion from the injection site. Five minutes later, cocaine $(10 \mathrm{mg} / \mathrm{kg}$, ip) or saline, i.p., was administered, and lever pressing was quantified. In one experiment, a combination of D1 (SCH-23390; $0.03 \mathrm{mg} / \mathrm{kg}$, ip) and D2 (raclopride; $0.3 \mathrm{mg} /$ $\mathrm{kg}$, ip) dopamine receptor antagonists was administered $10 \mathrm{~min}$ before cocaine-induced reinstatement.

\section{Whole-Cell Recordings in Acute Brain Slices}

Rats were anesthetized with ketamine $\mathrm{HCl}(87.5 \mathrm{mg} / \mathrm{kg}$, i.p.), and then brains were rapidly removed into ice-cold aCSF. Coronal slices $(230 \mu \mathrm{m}$ thick) containing the nucleus accumbens were cut in ice-cold aCSF with a vibratome and incubated in $32{ }^{\circ} \mathrm{C}$ aCSF (in mM: $126 \mathrm{NaCl}, 2.5 \mathrm{KCl}, 1.4$ $\mathrm{NaH}_{2} \mathrm{PO}_{4}, 1.2 \mathrm{MgCl}_{2}, 2.4 \mathrm{CaCl}_{2}, 25 \mathrm{NaHCO}_{3}$, and 11 glucose) for at least $45 \mathrm{~min}$ before returning to room temperature. Picrotoxin $(50 \mu \mathrm{M})$ was added to block $\mathrm{GABA}_{\mathrm{A}}$ receptormediated IPSCs during recording. Cells were visualized using infrared-differential interference contrast optics. To assess excitatory synaptic transmission, neurons were voltage clamped at $-80 \mathrm{mV}$ using a Multiclamp $700 \mathrm{~A}$ amplifier (Molecular Devices, Foster City, CA). Patch electrodes (1.5-2 M $\Omega$ ) were filled with internal solution containing (in mM) 124 Cesium Methanesulfonate, $10 \mathrm{NaCl}$, $1 \mathrm{MgCl}_{2}, 10$ HEPES, 1 EGTA, 1 QX-314, $2 \mathrm{MgATP}$, and 0.3 MgGTP (275-285 mOsm, pH 7.2-7.4). Series resistance $(<20 \mathrm{M} \Omega)$ and input resistance were monitored online with a $5-\mathrm{mV}$ depolarizing step $(100 \mathrm{~ms})$ given with each stimulus. Afferents were stimulated at $0.05 \mathrm{~Hz}$ by a concentric bipolar electrode placed about $150 \mu \mathrm{m}$ dorsomedial to the recorded neurons. The intensity of stimulation was chosen to evoke a 200-300 pA EPSC. Glutamatergic afferents were electrically stimulated, and the AMPA and NMDA currents were pharmacologically isolated by bath applying the NMDAR antagonist D-AP5 $(50 \mu \mathrm{M})$ at $+40 \mathrm{mV}$ clamping voltage. The synaptic strength was determined by the ratio of AMPAR- to NMDAR-mediated peak current (A/N ratio). 
For the measurement of AMPAR rectification, the internal solution contained $0.1 \mathrm{mM}$ spermine. The rectification index was calculated from the current-voltage (I-V) curve as a ratio of the slope at negative holding potentials ( $-80 \mathrm{mV}$ to reversal potential) divided by the slope at positive holding potentials (reversal potential to $+40 \mathrm{mV}$ ) (Clem and Huganir, 2010). All holding potentials were corrected for liquid junction potential. Data were filtered at $2 \mathrm{kHz}$, digitized at $5 \mathrm{kHz}$, and collected and analyzed using AxoGraph X software (AxoGraph Scientific, Sydney, Australia).

\section{Diolistic Labeling and Spine Morphology Quantification}

Animals were administered an overdose of pentobarbital $(100 \mathrm{mg} / \mathrm{kg}$, i.p.) and perfused through the heart with phosphate-buffered saline (PBS) followed by $2 \%$ paraformaldehyde in PBS. MSNs in the NAcore were labeled with DiI as described in detail elsewhere (Shen et al, 2011). Labeled neurons were imaged using a confocal microscope, and spine density and head diameter ( $d_{h}$; diameter of the vertex at the spine terminal point) were quantified following threedimensional rendering of the imaged neuron using the Imaris software package (Bitplane), as described in detail elsewhere (Shen et al, 2011). The images were deconvoluted by Autoquant (Media Cybernetics). Spine quantification commenced on dendrites beginning at $>75 \mu \mathrm{m}$ from the soma and after the first branch point. Measurements were made out to a maximum of $200 \mu \mathrm{m}$ from the soma, and the length of dendrite quantified was $40-55 \mu \mathrm{m}$ in length. At least 12 neurons per animal were analyzed.

\section{Statistics}

All spine density and diameter data were statistically analyzed after averaging multiple dendrite segment measurements for each neuron. When two groups were compared, the data were statistically analyzed using a two-tailed unpaired Student's $t$-test. For comparing the multiple measurements in the same experiment, the data were analyzed using a one-way or twoway ANOVA. A Tukey's post hoc test was applied for multiple comparisons and $p<0.05$ was considered statistically significant. All statistical tests are conducted using the SPSS (Chicago, IL) or Prism (Graphpad, La Jolla, CA) software.

\section{RESULTS}

\section{Acute Cocaine Priming Potentiated Synaptic Strength without Changing AMPA Current Rectification}

To investigate synaptic adaptations after extinction training and cocaine-induced reinstatement, animals underwent 2-3 weeks of extinction training immediately after 10 days of cocaine self-administration, and yoked saline animals were used as a control group (Figure 1a). Interestingly, although a relatively short-access paradigm (ie, daily 2 - $h$ cocaine selfadministration training over 10 days), animals demonstrated escalated lever pressing for cocaine, likely due to the absence of previous food training (one-way ANOVA with repeated measures over the first 10 days, $\left.\mathrm{F}_{(9,558)}=16.72, p<0.001\right)$. Figure $1 \mathrm{~b}$ shows that an acute cocaine injection $(10 \mathrm{mg} / \mathrm{kg}$, i.p.) reinstated active lever pressing during the first $45 \mathrm{~min}$ of the reinstatement session in cocaine-extinguished rats (oneway ANOVA, $\left.\mathrm{F}_{(4,58)}=38.84, p<0.001\right)$. However, in the cohort of animals killed at $15 \mathrm{~min}$ after cocaine injection, lever pressing was not yet significantly reinstated.

Either just before or $15 \mathrm{~min}, 45 \mathrm{~min}$ or $24 \mathrm{~h}$ after acute cocaine administration, coronal brain slices were prepared, and whole-cell patch recordings were made from MSNs in the NAcore. A one-way ANOVA revealed significant differences between the treatment groups $\left(\mathrm{F}_{(5,75)}=8.52\right.$, $p<0.001$; Figure 1c). A Tukey's post hoc multiple comparison analysis revealed that the basal $\mathrm{A} / \mathrm{N}$ (ie, rats killed $24 \mathrm{~h}$ after the last extinction session but before injecting acute cocaine) was greater in rats previously trained to selfadminister cocaine compared with yoked-saline rats. Although acute cocaine injection reinstated lever pressing only in rats extinguished from cocaine self-administration, the $\mathrm{A} / \mathrm{N}$ was elevated in both self-administration and yokedsaline groups at $45 \mathrm{~min}$ after injection. A more complete time course analysis in rats trained to self-administer cocaine revealed that acute cocaine did not increase $\mathrm{A} / \mathrm{N}$ by $15 \mathrm{~min}$ after injection, and the increase at $45 \mathrm{~min}$ after injection returned to the cocaine baseline by $24 \mathrm{~h}$ after injection. We did not replicate previous studies showing an LTD-like decrease in A/N or AMPA surface receptor expression at $24 \mathrm{~h}$ after acute cocaine administration in rats withdrawn from daily cocaine administration (Boudreau et al, 2007; Kourrich et al, 2007; Rothwell et al, 2011). This difference may result from the fact that the other studies utilized noncontingent, daily injections of cocaine, while the present study utilized the self-administration model. Alternatively, the NAcore may not show the LTD-like changes found in the NAshell (Kourrich and Thomas, 2009).

The increase in $A / \mathrm{N}$ can result from substitutions among AMPA receptor subunits (Liu and Zukin, 2007), and some studies find that the basal increase in $\mathrm{A} / \mathrm{N}$ after selfadministered cocaine results from an increase in GluA2lacking, $\mathrm{Ca}^{2+}$-permeable AMPA receptors in VTA dopamine neurons or accumbens MSNs (Bellone and Luscher, 2006; Conrad et al, 2008; McCutcheon et al, 2011). Therefore, we investigated whether the enhanced $\mathrm{A} / \mathrm{N}$ at $45 \mathrm{~min}$ after acute cocaine administration was accompanied by a change in AMPA receptor subtype. Evoked EPSCs were measured using a range from -80 to $+40 \mathrm{mV}$ clamping voltage in a spermine-containing bath that endows GluA2lacking AMPAR with inward rectification (Bowie and Mayer, 1995; Kamboj et al, 1995). We observed that neither cocaine training nor acute cocaine administration induced changes in the AMPA rectification index (two-way ANOVA, training $\mathrm{F}_{(1,67)}=0.15, p=0.699$; priming $\mathrm{F}_{(1,67)}=0.044$, $p=0.834$; interaction $\mathrm{F}_{(1,67)}=0.744, p=0.391$; Figure $1 \mathrm{~d}$ ). It is possible that extinction training may have eliminated the enhanced inward rectification previously observed in MSNs of cocaine-trained rats withdrawn but not undergoing daily extinction training (Conrad et al, 2008; McCutcheon et al, 2011).

\section{PL and VTA Afferents Differentially Regulate Cocaine-Reinstatement Associated Increases in $\mathrm{A} / \mathrm{N}$}

Previous studies have shown that neuronal activity in the PL or VTA is necessary for cocaine-induced reinstatement (McFarland and Kalivas, 2001). Figure 2a shows that 

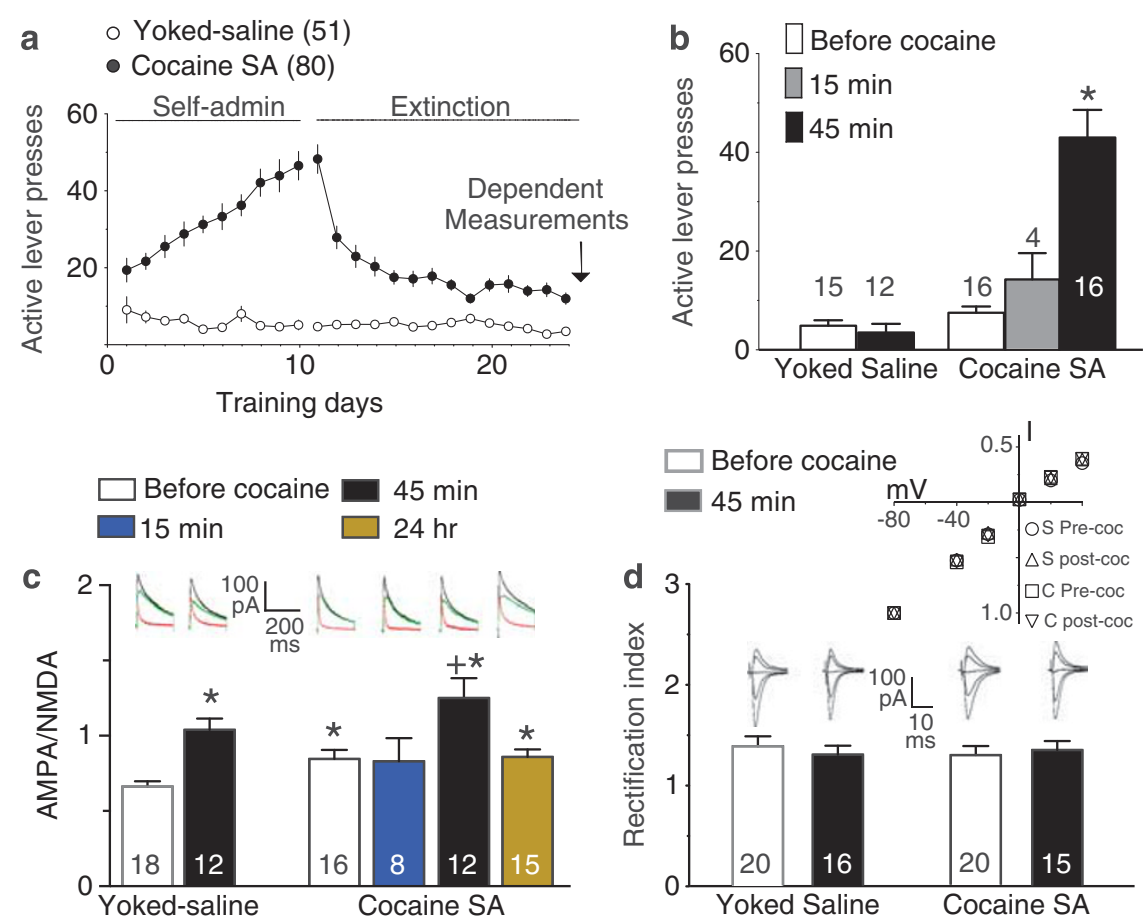

Figure I Acute cocaine administration potentiated A/N without changing the AMPA receptor rectification. (a) Active lever pressing in the cocaine and yoked-saline administration/extinction training protocol used for all experiments. (b) Acute cocaine reinstates active lever pressing in cocaine-extinguished rats. Histogram shows the active lever pressing over 15 or $45 \mathrm{~min}$ after acute cocaine administration (mean \pm SEM). Before cocaine refers to the last day of extinction pressing in rats that were killed $24 \mathrm{~h}$ later but before initiating a cocaine reinstatement session, and Cocaine SA refers to rats extinguished from cocaine self-administration. $\mathrm{N}$ shown in panel b corresponds to the number of rats assigned in electrophysiological and morphological experiments in panels $\mathrm{c}$ and $\mathrm{d}$ and Figure $3 \mathrm{~b}$. ${ }^{*} \mathrm{p}<0.05$ comparing active lever presses at $45 \mathrm{~min}$ after cocaine injection between the yoked-saline and cocaine groups using a Tukey's post hoc. (c) In the absence of an acute injection of cocaine, cocaine-extinguished rats exhibited higher A/N in NAcore MSNs than saline-yoked controls. Acute cocaine administration augmented the A/N in both Yoked-saline and Cocaine SA rats at 45 min after injection. * $p<0.05$ compared with the Yoked-saline/Before cocaine group using a Tukey's post hoc. ${ }^{+} p<0.05$, compared with Before cocaine within the Cocaine SA group. Traces illustrate the dual-component EPSC (black) and the pharmacologically isolated AMPA (red) and NMDA (green) currents from MSNs in each group. N shown in bars is the number of recorded neurons that are from 4-6 rats in each group. (d) Neither cocaine self-administration nor acute cocaine administration changed the AMPA rectification index. Traces are examples of evoked AMPA-mediated currents with holding voltage from -80 to $+40 \mathrm{mV}$. The insert shows the current-voltage (I-V) relationship for AMPA EPSCs in each group. N shown in bars is the number of recorded neurons that are from 4-6 rats in each group. S: saline-yoked group; C: cocaine-administered group; Pre-coc: before acute cocaine; Post-coc: 45 min after acute cocaine.

inhibiting the PL or VTA after microinjecting a combination of GABA agonists (baclofen + muscimol; B/M) did not alter active lever pressing in yoked-saline rats. However, Figure 2c shows that inhibiting either the PL or VTA prevented cocaine-induced reinstatement (two-way ANOVA; interaction $\left.\mathrm{F}_{(3,41)}=7.64, p<0.001\right)$. As in Figure 1, Figure $2 \mathrm{~b}$ shows that $45 \mathrm{~min}$ after acute cocaine administration in yoked-saline rats pretreated with aCSF in either the VTA or PL, the A/N was elevated compared with acute saline (two-way ANOVA; interaction $\left.\mathrm{F}_{(2,70)}=3.20, p=0.46\right)$. This increase was prevented by inactivation of the VTA but was unaffected by PL inactivation. VTA inactivation also prevented the increase in $\mathrm{A} / \mathrm{N}$ elicited by acute cocaine in rats extinguished from cocaine self-administration (Figure 2d; two-way ANOVA; interaction $\left.\mathrm{F}_{(3,85)}=5.43, p=0.002\right)$. In contrast to VTA inactivation, $\mathrm{B} / \mathrm{M}$ microinjection into the PL facilitated the acute cocaine-induced $\mathrm{A} / \mathrm{N}$ in rats extinguished from cocaine self-administration. The VTA is rich in dopamine neurons projecting to the NAcore (Fallon et al, 1978). Thus, we hypothesized that blocking dopamine receptors would mimic the effect of VTA inactivation. Figure $2 c$ shows that, akin to VTA inactivation, animals pretreated with a combination of the D1 (SCH-23390, $0.03 \mathrm{mg} / \mathrm{kg}$, i.p.) and D2 (raclopride,
$0.3 \mathrm{mg} / \mathrm{kg}$, i.p.) dopamine receptor antagonists $10 \mathrm{~min}$ before injecting cocaine prevented both reinstated cocaine seeking (Figure 2c) and the increase in $\mathrm{A} / \mathrm{N}$ (Figure 2d) induced by acute cocaine administration.

\section{Acute Cocaine Induced a VTA-Dependent Increase in Spine Head Diameter $\left(d_{h}\right)$ only in Rats Extinguished from Cocaine Self-Administration}

Acute cocaine-induced potentiation in $\mathrm{A} / \mathrm{N}$ may be associated with a concurrent increase in $d_{h}$ to accommodate newly inserted AMPA receptors (Collingridge et al, 2004; Lamprecht and LeDoux, 2004; McKinney, 2010). Spine density and $d_{h}$ in NAcore MSNs were quantified following diolistic labeling with the lipophilic dye DiI (Figure 2a shows an example of a DiI-labeled neuron and a dendrite segment to be quantified). There was no difference between the treatment groups in spine density (Yoked-saline, Before cocaine $=2.56 \pm 0.07$ spines $/ \mu \mathrm{m}, \quad N=59 ; \quad$ yoked-saline, $\quad 45 \mathrm{~min}=2.50 \pm 0.07$, $N=53$; cocaine SA, Before cocaine $=2.62 \pm 0.07, N=86$; cocaine SA, $45 \mathrm{~min}=2.70 \pm 0.09, \quad N=70 ;$ cocaine $\mathrm{SA}$, $24 \mathrm{~h}=2.66 \pm 0.13, N=66)$. However, extinction from cocaine self-administration increased $d_{h}$ (Figure $3 \mathrm{~b}$, one-way ANOVA, 

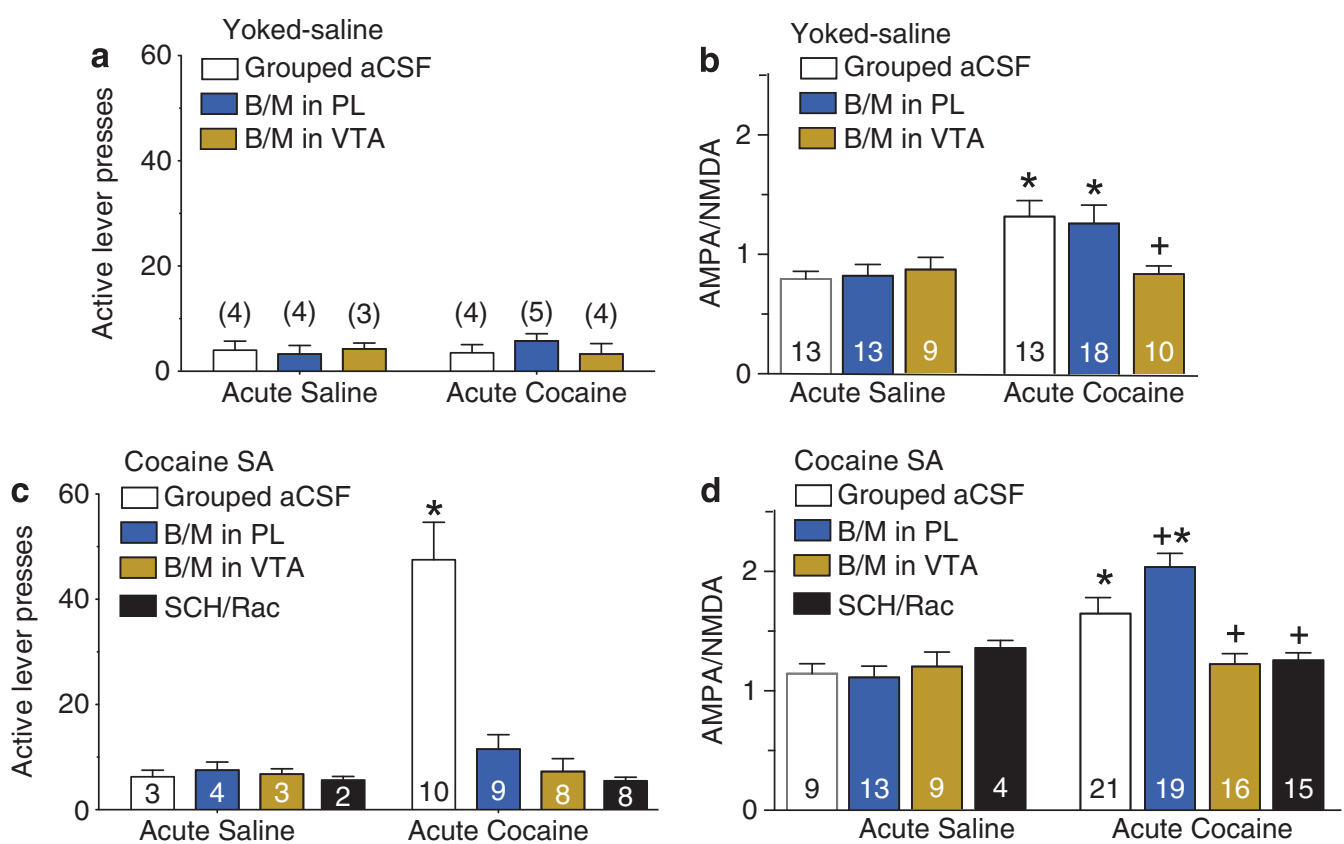

Figure 2 The cocaine-induced $A / N$ is differentially regulated by pharmacological inactivation of the PL and VTA. (a) Previous microinjection GABA receptor agonist (B/M) into the PL or VTA did not affect active lever pressing in yoked-saline animals. N in parentheses corresponds to the number of animals used to generate the A/N data in panel b. (b) Inactivation of the VTA, but not the PL, inhibited acute cocaine-induced potentiation in A/N in yokedsaline rats. $\mathrm{N}$ in the bar is the number of cells recorded. (c) Inactivation of the PL or VTA or systemic administration of the dopamine antagonists SCH-23390 ( $\mathrm{SCH} ; 0.03 \mathrm{mg} / \mathrm{kg}$, ip) plus raclopride (Rac; $0.3 \mathrm{mg} / \mathrm{kg}$, ip) prevented cocaine-induced reinstatement. $\mathrm{N}$ in bars corresponds to the number of animals used to generate the A/N data in panel d. (d) PL inactivation facilitated but VTA inactivation or SCH/Rac injection prevented acute cocaine-induced potentiation in $\mathrm{A} / \mathrm{N}$ in cocaine-extinguished rats. $\mathrm{N}$ in bars is the number of cells recorded. Grouped aCSF refers to a combination of control animals microinjected with aCSF in either the VTA or PL plus animals receiving systemic vehicle injections as controls for the $\mathrm{SCH} / \mathrm{Rac}$ treatment. The data are shown as mean \pm SEM over the $45 \mathrm{~min}$ after acute cocaine or vehicle administration. ${ }^{*} p<0.05$ comparing the acute cocaine to acute saline within each treatment group within a given panel. ${ }^{+} p<0.05$ comparing the effect of acute cocaine in the PL, VTA, or SCH/Rac groups to the Grouped aCSF group.

$\left.\mathrm{F}_{(1,329)}=9.55, p<0.001\right)$. Spine head diameter was further increased in cocaine-trained subjects at $45 \mathrm{~min}$ after an acute cocaine injection, and $d_{h}$ returned to basal levels by $24 \mathrm{~h}$ after acute cocaine. Interestingly, and in contrast with $\mathrm{A} / \mathrm{N}$, acute cocaine administration in yoked-saline rats did not increase $d_{h}$. The cumulative distribution plot of $d_{h}$ for rats extinguished from cocaine self-administration revealed that cocaine-induced reinstatement produced a significant rightward shift in distribution that arose primarily from a significant reduction in spines with $d_{h}<0.35 \mu \mathrm{m}$ (two-way ANOVA, interaction $\left.\mathrm{F}_{(12,1533)}=15.77, p<0.001\right)$.

GABA agonists were microinjected to determine whether the cocaine-induced increases in $d_{h}$ depended on neuronal activity in the VTA or PL. Figure $3 \mathrm{c}$ shows that, akin to the increase in $\mathrm{A} / \mathrm{N}$, inhibiting activity in the VTA prevented the increase in $d_{h}$ produced $45 \mathrm{~min}$ after acute administration of cocaine in rats extinguished from cocaine selfadministration (one-way ANOVA, $\mathrm{F}_{(2,206)}=9.96, p<0.001$ ). The cumulative distribution analysis showed that the reduction in mean $d_{h}$ following VTA inhibition resulted from increasing the population of spines with $<0.35 \mu \mathrm{m}$ diameter. Although post hoc analysis revealed that the mean $d_{h}$ was not affected by inhibiting PL, the cumulative distribution plot showed that $\mathrm{B} / \mathrm{M}$ microinjection into the PL further increased $d_{h}$ in spines in the range of $0.35-0.5 \mu \mathrm{m}$ (two-way ANOVA, interaction $\mathrm{F}_{(12,1456)}=13.98, p<0.001$ ). There was no difference in spine density between any treatment groups in Figure $3 c$ (Grouped aCSF $=2.65 \pm 0.11$ spines $/ \mu \mathrm{m}, \quad N=86 ; \quad \mathrm{B} / \mathrm{M} \quad \mathrm{PL}=2.55 \pm 0.06, \quad N=69 ; \quad \mathrm{B} / \mathrm{M}$ $\mathrm{VTA}=2.42 \pm 0.08, N=56$ ).

\section{DISCUSSION}

Our data show that reinstating animals extinguished from cocaine self-administration with an acute injection of cocaine induced an LTP-like increase in $\mathrm{A} / \mathrm{N}$ and $d_{h}$. The synaptic potentiation was not present at $15 \mathrm{~min}$ after injection but was expressed by $45 \mathrm{~min}$ and subsided by $24 \mathrm{~h}$ after injection. This time course parallels the behavioral reinstatement that had not begun by $15 \mathrm{~min}$ but was strongly manifested by $45 \mathrm{~min}$ after injection. Finally, the LTP-like plasticity was found to be dopamine dependent as it was prevented by either pharmacological inactivation of the VTA or by systemic administration of combined D1 and D2 dopamine receptor antagonists.

\section{Association Between Behavioral Reinstatement and LTP-Like Increases in $\mathrm{A} / \mathrm{N}$ and $\boldsymbol{d}_{\boldsymbol{h}}$}

The increased $\mathrm{A} / \mathrm{N}$ and $d_{h}$ also resembles our recent findings that reinstating cocaine seeking with either a Pavlovian cue or the context that was associated with cocaine self-administration elicits an increase in $\mathrm{A} / \mathrm{N}$ or $d_{h}$ in the NAcore (Gipson et al, 2013a; Stankeviciute et al, 2013). In all of these studies, the behavioral time course for 

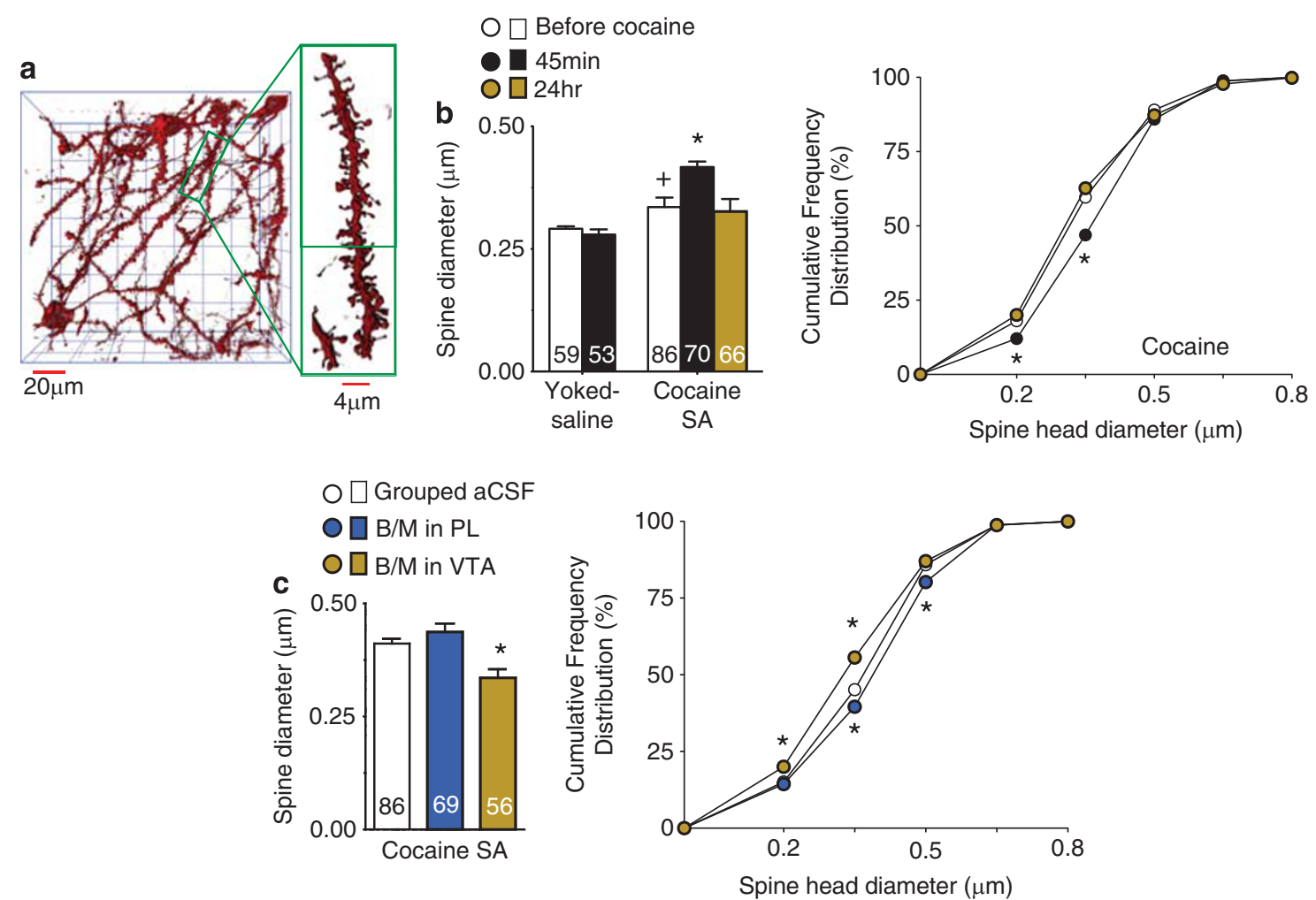

Figure 3 Cocaine reinstatement for 45 min increased $d_{h}$ in MSNs in rats extinguished from cocaine self-administration (for behavioral data, see Figure Ia and b). (a) Example of neuron and dendritic segment quantified for spine morphology. (b) Left, Cocaine SA rats showed a basal increase in mean $d_{h}$ compared with Yoked-saline animals, and acute cocaine administration further increased $d_{h}$ only in Cocaine SA rats. Data are shown as mean \pm SEM. $N=$ number of neurons quantified shown in each bar, obtained from 4-6 rats. Right, the cumulative frequency distribution of spine $d_{h}$ showing shift to the right $45 \mathrm{~min}$ after acute cocaine administration in cocaine-extinguished rats. (c) Left, inactivation of the VTA, but not the PL, prevented the increase in $d_{h}$ at $45 \mathrm{~min}$ after acute cocaine administration in Cocaine SA rats. Right, cumulative distribution plots of $d_{h}$ demonstrate a shift to the left by inactivation of the VTA and to the right by inactivating the PL compared with the distribution induced by acute cocaine administration in aCSF-microinjected, Cocaine SA rats. Grouped aCSF refers to the pooling of data from animals microinjected with aCSF into either the VTA and PL. ${ }^{+} p<0.05$ comparing basal $d_{h}($ Before cocaine) between Yoked-saline and Cocaine SA. ${ }^{*} p<0.05$ compared with basal $d_{h}$ in Cocaine SA rats.

reinstated behavior paralleled the LTP-like changes. Thus, behavior, $\mathrm{A} / \mathrm{N}$, and $d_{h}$ were all maximal for cue- and contextreinstated behavior at $15 \mathrm{~min}$, while cocaine-induced reinstatement and synaptic potentiation was not present at $15 \mathrm{~min}$ but was manifested by $45 \mathrm{~min}$ after injection. A similar parallel time course between behavior synaptic potentiation was also measured after cue-induced reinstatement of nicotine seeking (Gipson et al, 2013b) and heroin-induced heroin seeking (Shen et al, 2011). Taken together, these findings support an argument that regardless of the chemical drug class or modality of stimulus, reinstating operant responding for addictive drugs induces an LTP-like synaptic potentiation at excitatory synapses on MSNs in the NAcore.

\section{Acute Cocaine Administration in Control Animals Produces Synaptic Potentiation}

Surprisingly, when cocaine was acutely administered to yoked-saline animals there was an equivalent increase in $\mathrm{A} / \mathrm{N}$ as was elicited in animals extinguished from cocaine self-administration. This is distinct from studies with cue-induced reinstatement where presentation of cocaineor nicotine-conditioned cues or an injection of heroin to yoked-saline animals did not alter A/N or $d_{h}$ (Gipson et al, 2013a; Shen et al, 2011; Stankeviciute et al, 2013). Also, acute cocaine administration in yoked-saline animals did not increase surface expression of GluA1 in the NAcore (Anderson et al, 2008). However, it is possible that elevated $\mathrm{A} / \mathrm{N}$ could result from a movement of receptors from the synaptic annulus into the synaptic cleft, which need not require increased surface AMPA receptors. It seems likely that the difference between cue- or heroin-reinstatement and cocaine-induced reinstatement may be related to the more robust increase in dopamine transmission produced in the accumbens by an acute cocaine injection relative to presentation of a reward-associated Pavlovian cue or heroin (Hemby et al, 1995; Ikegami et al, 2007; Ito et al, 2000). Work by Wolf and colleagues demonstrates that D1 receptor stimulation increases in GluA1-containing AMPA receptor surface expression in vivo or in cultured neurons, regardless of whether animals have been pretreated with cocaine (Chao et al, 2002; Gao et al, 2006; Mangiavacchi and Wolf, 2004; Sun et al, 2008). However, the same group reported that acute stimulation of D2 dopamine receptors increases endocytosis of accumbens GluA1 and GluA2 receptors (Ferrario et al, 2011). In future studies, it will be of interest to use mice selectively expressing D1 or D2 marker proteins to determine whether cocaine increases in dopamine transmission may differentially regulate these two distinct populations of $\mathrm{MSN}$; although differential 
changes in two roughly equivalent populations was not indicated by the normal distribution of $\mathrm{A} / \mathrm{N}$ in our experiments.

It is important to consider that, in addition to affecting afferents or receptors in the NAcore, pharmacological inhibition in the VTA and PL, or systemic administration of dopamine antagonists, will also modulate other brain regions that can indirectly affect NAcore synaptic transmission. Although optogenetic inactivation of the PL and VTA projections to the NAcore supports a specific role for NAcore innervation by these afferents in reinstated cocaine seeking (Stefanik et al, 2013a; Stefanik et al, 2013b), similar optogenetic studies are needed to prove that the effects found in the present study on synaptic plasticity are as selectively regulated. Another consideration is that cocaine blocks serotonin and norepinephrine transport (Ritz et al, 1990), and increasing levels of these transmitters may contribute to our findings. However, the fact that inhibiting dopamine cells in the VTA prevented cocaine-induced synaptic plasticity in NAcore supports a primary action on dopamine transmission.

Although all of these data are generally consistent with acute cocaine producing a dopamine-dependent increase in $\mathrm{A} / \mathrm{N}$ regardless of the animals previous exposure to cocaine, it is interesting that an increase in $d_{h}$ by acute cocaine occurred only in rats previously trained to self-administer cocaine. Similarly, it was previously found that $d_{h}$ decreased in parallel with cue-reinstated lever pressing at $45 \mathrm{~min}$ after initiating the reinstatement session, while the cue-induced increase in $\mathrm{A} / \mathrm{N}$ endured for up to $120 \mathrm{~min}$ (Gipson et al, 2013a). Also, the increase in $d_{h}$ produced during heroininduced reinstatement transiently decreased with behavior by $120 \mathrm{~min}$ after injection, while an LTP-like increase in field potential amplitude persisted for nearly $180 \mathrm{~min}$ (Shen et al, 2011). Although many studies have shown parallel changes in AMPA currents and spine morphology during LTP and LTD (Gu et al, 2010; Lang et al, 2004; Passafaro et al, 2003; Zhou et al, 2004), other studies find that the signaling mechanisms underlying increased AMPA signaling and spine enlargement can diverge (Fukazawa et al, 2003; Lu et al, 2013). Thus, it is conceivable that D1 receptor stimulation could increase synaptic AMPA signaling without altering spine morphology while reinstating drug seeking, regardless of whether initiated by cue, context, heroin, or cocaine increases both $\mathrm{A} / \mathrm{N}$ and $d_{h}$.

\section{Role for the PL and VTA in Regulating Reinstatement and the Associated LTP-Like Synaptic Plasticity}

Neuronal activity in PL glutamatergic afferents to the NAcore is necessary to induce reinstatement by cocaine or cues (Park et al, 2002; Stefanik et al, 2013b). Reinstatement and accumbens synaptic plasticity have also been shown to depend on the activity of neurons in the VTA (Mameli et al, 2009; McFarland and Kalivas, 2001). Consistent with these findings, we showed that pharmacological inactivation of either the VTA or PL blocked cocaine-induced reinstatement of active lever pressing. Directly supporting the involvement of dopamine transmission, simultaneous antagonism of D1 and D2 dopamine receptors with systemically administered SCH-23390 and raclopride also prevented cocaine-induced reinstatement. In contrast to reinstatement, the capacity of VTA or PL inactivation to prevent the LTP-like changes induced by acute cocaine administration diverged. Consistent with dependence on dopamine transmission, VTA inhibition prevented acute cocaine-induced $\mathrm{A} / \mathrm{N}$ and $d_{h}$, in yoked-saline and cocaine self-administration rats. However, PL inactivation potentiated cocaine-induced increases in $\mathrm{A} / \mathrm{N}$ and $d_{h}$ in rats extinguished from cocaine self-administration and was without effect on the increase in $\mathrm{A} / \mathrm{N}$ produced by acute cocaine in yoked-saline animals. This demonstrates that the LTP-like plasticity is necessary, but not sufficient, to induce reinstatement. Furthermore, PL and VTA differentially coordinate the potentiation of synaptic strength in the NAcore induced by a cocaine priming injection in a manner that is necessary to reinstate behavior. The potentiation by $\mathrm{PL}$ inactivation is a surprising contrast to our previous report in which $\mathrm{PL}$ inactivation prevented cue-induced increases in $\mathrm{A} / \mathrm{N}$ and $d_{h}$ (Gipson et al, 2013a). These contradictory findings regarding how PL inactivation alters cue- $v s$ cocaine-induced synaptic potentiation indicates that the role of the $\mathrm{PL}$ in regulating reinstatement-associated plasticity may be state-dependent.

Neuroimaging studies reveal that activation of human anterior cingulate (homologue of the rat PL) is associated with a diverse range of tasks involving monitoring and determining the dynamic value of behavior, as well as in selecting appropriate behavioral responses (Bush et al, 2000; Goldstein et al, 2009; Walton et al, 2007). Thus, PL activation can yield seemingly contradictory results when applied to different models of addiction depending on whether responding or not responding is the most adaptive response. For example, optogenetically inhibiting the PL promotes cocaine seeking in model of compulsive operant responding when cocaine delivery is associated with punishment, because the PL is important for devaluing cocaine in the presence of punishment (Chen et al, 2013). In contrast, optogenetic or pharmacological inhibition of the $\mathrm{PL}$ prevents reinstated cocaine seeking where the $\mathrm{PL}$ is necessary for recognizing the value of the cocaine-conditioned cues (McFarland and Kalivas, 2001; Stefanik et al, 2013b). Interestingly, both the Chen et al (2013) study and the present data indicate that neuronal activity in $\mathrm{PL}$ inhibits the effects of cocaine-induced dopamine release, in the former devaluing cocaine reinforcement relative to punishment and in our study reducing acute cocaineinduced, dopamine-dependent synaptic potentiation in NAcore MSNs. Together, these studies indicate that PL activity may not only serve to limit the physiological impact of cocaine-induced dopamine transmission in the accumbens to reinforce behavior and induce synaptic potentiation but can also serve to signal cocaine seeking in response to a drug-associated stimulus. Finally, PL inhibition did not alter the increase in $\mathrm{A} / \mathrm{N}$ produced in yoked-saline animals by acute cocaine administration, indicating that involvement of the PL in regulating cocaine-dependent synaptic plasticity occurs only after repeated cocaine experience.

\section{CONCLUSIONS}

Our observations add to a wide literature showing that environmental stimuli induce dendritic spine remodeling 
and AMPA receptor trafficking ( $\mathrm{Fu}$ et al, 2012; Holtmaat and Svoboda, 2009; Kessels and Malinow, 2009; Lai et al, 2012). In the case of synaptic plasticity elicited by acute cocaine on MSNs in the NAcore, we found that cocaineinduced changes in $\mathrm{A} / \mathrm{N}$ and $d_{h}$ depend on dopamine transmission. Given that synaptic potentiation occurs in response to a variety of stimuli that reinstate operant responding and in animals trained to self-administer many addictive drugs, including cocaine, nicotine, or heroin (Anderson et al, 2008; Gipson et al, 2013a; Gipson et al, 2013b; Shen et al, 2011; Stankeviciute et al, 2013), this transient plasticity seems necessary, although not sufficient (see above), for reinstatement to occur. Thus, discerning the cellular processes that uniquely underlie reinstatementassociated synaptic plasticity could be a fruitful avenue of drug development for treating relapse in drug addiction.

\section{FUNDING AND DISCLOSURE}

The authors declare no conflict of interest.

\section{ACKNOWLEDGEMENTS}

This work was supported by the DA007288, DA03906, DA012513, and DA015369 grants from the National Institutes of Health.

\section{REFERENCES}

Anderson SM, Famous KR, Sadri-Vakili G, Kumaresan V, Schmidt HD, Bass CE et al (2008). CaMKII: a biochemical bridge linking accumbens dopamine and glutamate systems in cocaine seeking. Nat Neurosci 11: 344-353.

Bellone C, Luscher C (2006). Cocaine triggered AMPA receptor redistribution is reversed in vivo by mGluR-dependent longterm depression. Nat Neurosci 9: 636-641.

Boudreau AC, Reimers JM, Milovanovic M, Wolf ME (2007). Cell surface AMPA receptors in the rat nucleus accumbens increase during cocaine withdrawal but internalize after cocaine challenge in association with altered activation of mitogen-activated protein kinases. J Neurosci 27: 10621-10635.

Bowie D, Mayer ML (1995). Inward rectification of both AMPA and kainate subtype glutamate receptors generated by polyaminemediated ion channel block. Neuron 15: 453-462.

Bush G, Luu P, Posner MI (2000). Cognitive and emotional influences in anterior cingulate cortex. Trends Cogn Sci 4: 215-222.

Chao SZ, Ariano MA, Peterson DA, Wolf ME (2002). D1 dopamine receptor stimulation increases GluR1 surface expression in nucleus accumbens neurons. J Neurochem 83: 704-712.

Chen BT, Yau HJ, Hatch C, Kusumoto-Yoshida I, Cho SL, Hopf FW et al (2013). Rescuing cocaine-induced prefrontal cortex hypoactivity prevents compulsive cocaine seeking. Nature 496: 359-362.

Clem RL, Huganir RL (2010). Calcium-permeable AMPA receptor dynamics mediate fear memory erasure. Science 330: 1108-1112.

Collingridge GL, Isaac JT, Wang YT (2004). Receptor trafficking and synaptic plasticity. Nat Rev Neurosci 5: 952-962.

Conrad KL, Tseng KY, Uejima JL, Reimers JM, Heng LJ, Shaham Y et al (2008). Formation of accumbens GluR2-lacking AMPA receptors mediates incubation of cocaine craving. Nature 454: $118-121$.

Fallon J, Koziell D, Moore R (1978). Catecholamine innervation of the basal forebrain. J Comp Neurol 180: 509-532.

Feltenstein MW, See RE (2008). The neurocircuitry of addiction: an overview. Br J Pharmacol 154: 261-274.
Ferrario CR, Li X, Wolf ME (2011). Effects of acute cocaine or dopamine receptor agonists on AMPA receptor distribution in the rat nucleus accumbens. Synapse 65: 54-63.

Fu M, Yu X, Lu J, Zuo Y (2012). Repetitive motor learning induces coordinated formation of clustered dendritic spines in vivo. Nature 483: 92-95.

Fukazawa Y, Saitoh Y, Ozawa F, Ohta Y, Mizuno K, Inokuchi K (2003). Hippocampal LTP is accompanied by enhanced F-actin content within the dendritic spine that is essential for late LTP maintenance in vivo. Neuron 38: 447-460.

Gao C, Sun X, Wolf ME (2006). Activation of D1 dopamine receptors increases surface expression of AMPA receptors and facilitates their synaptic incorporation in cultured hippocampal neurons. J Neurochem 98: 1664-1677.

Gipson CD, Kupchik YM, Shen H, Reissner KJ, Thomas CA, Kalivas PW (2013a). Relapse induced by cues predicting cocaine depends on rapid, transient synaptic potentiation. Neuron 77: 867-872.

Gipson CD, Reissner KJ, Kupchik YM, Smith AC, Stankeviciute N, Hensley-Simon ME et al (2013b). Reinstatement of nicotine seeking is mediated by glutamatergic plasticity. Proc Natl Acad Sci USA 110: 9124-9129.

Goldstein RZ, Craig AD, Bechara A, Garavan H, Childress AR, Paulus MP et al (2009). The neurocircuitry of impaired insight in drug addiction. Trends Cogn Sci 13: 372-380.

Gu J, Lee CW, Fan Y, Komlos D, Tang X, Sun C et al (2010). ADF/ cofilin-mediated actin dynamics regulate AMPA receptor trafficking during synaptic plasticity. Nat Neurosci 13: 1208-1215.

Hemby SE, Martin TJ, Co C, Dworkin SI, Smith JE (1995). The effects of intravenous heroin administration on extracellular nucleus accumbens dopamine concentrations as determined by in vivo microdialysis. J Pharmacol Exp Ther 273: 591-598.

Holtmaat A, Svoboda K (2009). Experience-dependent structural synaptic plasticity in the mammalian brain. Nat Rev Neurosci 10: 647-658.

Ikegami A, Olsen CM, D'Souza MS, Duvauchelle CL (2007). Experience-dependent effects of cocaine self-administration/ conditioning on prefrontal and accumbens dopamine responses. Behav Neurosci 121: 389-400.

Ito R, Dalley JW, Howes SR, Robbins TW, Everitt BJ (2000). Dissociation in conditioned dopamine release in the nucleus accumbens core and shell in response to cocaine cues and during cocaine-seeking behavior in rats. J Neurosci 20: 7489-7495.

Ito R, Dalley JW, Robbins TW, Everitt BJ (2002). Dopamine release in the dorsal striatum during cocaine-seeking behavior under the control of a drug-associated cue. J Neurosci 22: 6247-6253.

Kamboj SK, Swanson GT, Cull-Candy SG (1995). Intracellular spermine confers rectification on rat calcium-permeable AMPA and kainate receptors. J Physiol 486(Pt 2): 297-303.

Kasanetz F, Deroche-Gamonet V, Berson N, Balado E, Lafourcade M, Manzoni O et al (2010). Transition to addiction is associated with a persistent impairment in synaptic plasticity. Science 328: 1709-1712.

Kessels HW, Malinow R (2009). Synaptic AMPA receptor plasticity and behavior. Neuron 61: 340-350.

Kourrich S, Rothwell PE, Klug JR, Thomas MJ (2007). Cocaine experience controls bidirectional synaptic plasticity in the nucleus accumbens. J Neurosci 27: 7921-7928.

Kourrich S, Thomas MJ (2009). Similar neurons, opposite adaptations: psychostimulant experience differentially alters firing properties in accumbens core versus shell. J Neurosci 29: 12275-12283.

Lai CS, Franke TF, Gan WB (2012). Opposite effects of fear conditioning and extinction on dendritic spine remodelling. Nature 483: 87-91.

Lamprecht R, LeDoux J (2004). Structural plasticity and memory. Nat Rev Neurosci 5: 45-54. 
Lang C, Barco A, Zablow L, Kandel ER, Siegelbaum SA, Zakharenko SS (2004). Transient expansion of synaptically connected dendritic spines upon induction of hippocampal long-term potentiation. Proc Natl Acad Sci USA 101: 16665-16670.

Liu SJ, Zukin RS (2007). Ca2+-permeable AMPA receptors in synaptic plasticity and neuronal death. Trends Neurosci 30: 126-134.

Lu W, Bushong EA, Shih TP, Ellisman MH, Nicoll RA (2013). The cell-autonomous role of excitatory synaptic transmission in the regulation of neuronal structure and function. Neuron 78: 433-439.

Luscher C, Malenka RC (2011). Drug-evoked synaptic plasticity in addiction: from molecular changes to circuit remodeling. Neuron 69: 650-663.

Mameli M, Halbout B, Creton C, Engblom D, Parkitna JR, Spanagel $\mathrm{R}$ et al (2009). Cocaine-evoked synaptic plasticity: persistence in the VTA triggers adaptations in the NAc. Nat Neurosci 12: 1036-1041.

Mangiavacchi S, Wolf ME (2004). D1 dopamine receptor stimulation increases the rate of AMPA receptor insertion onto the surface of cultured nucleus accumbens neurons through a pathway dependent on protein kinase A. J Neurochem 88: 1261-1271.

Martin M, Chen BT, Hopf FW, Bowers MS, Bonci A (2006). Cocaine self-administration selectively abolishes LTD in the core of the nucleus accumbens. Nat Neurosci 9: 868-869.

McCutcheon JE, Wang X, Tseng KY, Wolf ME, Marinelli M (2011). Calcium-permeable AMPA receptors are present in nucleus accumbens synapses after prolonged withdrawal from cocaine self-administration but not experimenter-administered cocaine. J Neurosci 31: 5737-5743.

McFarland K, Kalivas PW (2001). The circuitry mediating cocaineinduced reinstatement of drug-seeking behavior. J Neurosci 21: 8655-8663.

McKinney RA (2010). Excitatory amino acid involvement in dendritic spine formation, maintenance and remodelling. J Physiol 588(Pt 1): 107-116.

McLaughlin J, See RE (2003). Selective inactivation of the dorsomedial prefrontal cortex and the basolateral amygdala attenuates conditioned-cued reinstatement of extinguished cocaine-seeking behavior in rats. Psychopharmacology (Berl) 168: 57-65.

Moussawi K, Pacchioni A, Moran M, Olive MF, Gass JT, Lavin A et al (2009). N-Acetylcysteine reverses cocaine-induced metaplasticity. Nat Neurosci 12: 182-189.

O’Brien CP, Gardner EL (2005). Critical assessment of how to study addiction and its treatment: human and non-human animal models. Pharmacol Ther 108: 18-58.

Park WK, Bari AA, Jey AR, Anderson SM, Spealman RD, Rowlett JK et al (2002). Cocaine administered into the medial prefrontal cortex reinstates cocaine-seeking behavior by increasing AMPA receptor-mediated glutamate transmission in the nucleus accumbens. J Neurosci 22: 2916-2925.

Passafaro M, Nakagawa T, Sala C, Sheng M (2003). Induction of dendritic spines by an extracellular domain of AMPA receptor subunit GluR2. Nature 424: 677-681.

Pierce RC, Wolf ME (2013). Psychostimulant-induced neuroadaptations in nucleus accumbens AMPA receptor transmission. Cold Spring Harb Perspect Med 3: a012021.

Ritz MC, Cone EJ, Kuhar MJ (1990). Cocaine inhibition of ligand binding at dopamine, norepinephrine and serotonin transporters: a structure-activity study. Life Sci 46: 635-645.
Robinson TE, Berridge KC (2000). The psychology and neurobiology of addiction: an incentive-sensitization view. Addiction 95(Suppl 2): S91-117.

Robinson TE, Kolb B (2004). Structural plasticity associated with exposure to drugs of abuse. Neuropharmacology 47(Suppl 1): 33-46.

Rothwell PE, Kourrich S, Thomas MJ (2011). Synaptic adaptations in the nucleus accumbens caused by experiences linked to relapse. Biol Psychiatry 69: 1124-1126.

Russo SJ, Dietz DM, Dumitriu D, Morrison JH, Malenka RC, Nestler EJ (2010). The addicted synapse: mechanisms of synaptic and structural plasticity in nucleus accumbens. Trends Neurosci 33: $267-276$

Sesack SR, Grace AA (2010). Cortico-basal ganglia reward network: microcircuitry. Neuropsychopharmacology 35: 27-47.

Shen H, Moussawi K, Zhou W, Toda S, Kalivas PW (2011). Heroin relapse requires long-term potentiation-like plasticity mediated by NMDA2b-containing receptors. Proc Natl Acad Sci USA 108: 19407-19412.

Shen HW, Toda S, Moussawi K, Bouknight A, Zahm DS, Kalivas PW (2009). Altered dendritic spine plasticity in cocaine-withdrawn rats. J Neurosci 29: 2876-2884.

Stankeviciute NM, Scofield MD, Kalivas PW, Gipson CD (2013). Rapid, transient potentiation of dendritic spines in contextinduced relapse to cocaine seeking. Addict Biol (advance online publication, 6 May 2013; doi:10.1111/adb.12064).

Stefanik MT, Kupchik YM, Brown RM, Kalivas PW (2013a). Optogenetic evidence that pallidal projections, not nigral projections, from the nucleus accumbens core are necessary for reinstating cocaine seeking. J Neurosci 33: 13654-13662.

Stefanik MT, Moussawi K, Kupchik YM, Smith KC, Miller RL, Huff ML et al (2013b). Optogenetic inhibition of cocaine seeking in rats. Addict Biol 18: 50-53.

Stewart J, de Wit H, Eikelboom R (1984). Role of unconditioned and conditioned drug effects in the self-administration of opiates and stimulants. Psychol Rev 91: 251-268.

Stuber GD, Britt JP, Bonci A (2011). Optogenetic modulation of neural circuits that underlie reward seeking. Biol Psychiatry 71: 1061-1067.

Sun W, Akins CK, Mattingly AE, Rebec GV (2005). Ionotropic glutamate receptors in the ventral tegmental area regulate cocaine-seeking behavior in rats. Neuropsychopharmacology 30: 2073-2081.

Sun X, Milovanovic M, Zhao Y, Wolf ME (2008). Acute and chronic dopamine receptor stimulation modulates AMPA receptor trafficking in nucleus accumbens neurons cocultured with prefrontal cortex neurons. J Neurosci 28: 4216-4230.

Volkow ND, Wang GJ, Telang F, Fowler JS, Logan J, Childress AR et al (2006). Cocaine cues and dopamine in dorsal striatum: mechanism of craving in cocaine addiction. J Neurosci 26: 6583-6588.

Walton ME, Croxson PL, Behrens TE, Kennerley SW, Rushworth MF (2007). Adaptive decision making and value in the anterior cingulate cortex. Neuroimage 36(Suppl 2): T142-T154.

Wolf ME, Ferrario CR (2010). AMPA receptor plasticity in the nucleus accumbens after repeated exposure to cocaine. Neurosci Biobehav Rev 35: 185-211.

Zhou Q, Homma KJ, Poo MM (2004). Shrinkage of dendritic spines associated with long-term depression of hippocampal synapses. Neuron 44: 749-757. 